\title{
Mental health quality and outcome measurement and improvement in Australia Peggy Brown ${ }^{\mathrm{a}, \mathrm{b}}$ and Jane Pirkis ${ }^{\mathrm{c}}$
}

\author{
aCT Health, ' Department of Psychological Medicine, \\ Australian National University, Canberra and ${ }^{\mathrm{C}}$ Centre \\ for Health Policy, Programs and Economics, Melbourne \\ School of Population Health, University of Melbourne, \\ Melbourne, Victoria, Australia \\ Correspondence to Peggy Brown, MB, BS (Hons) \\ FRANZCP, Mental Health, ACT Health, Adjunct \\ Associate Professor, Department of Psychological \\ Medicine, Australian National University, Canberra, \\ Australia \\ Tel: +612 62051313; \\ e-mail: peggy.brown@act.gov.au
}

Current Opinion in Psychiatry 2009, 22:610-618

\section{Purpose of review}

This study outlines the broad approach taken in Australia to improve the quality of mental health services, including the use of performance and outcome measures along with a range of other linked quality initiatives.

\section{Recent findings}

The investment of Australia in a strategic national approach to mental health reform with a range of nationally coordinated quality initiatives has provided a firm foundation for continuing to engage governments, healthcare organizations and clinicians in the ongoing quest for quality and outcome measurement and improvement.

\section{Summary}

Australia has adopted a strategic national approach to quality and outcome measurement and improvement of mental health services despite having a federated health system involving nine governments and tiered care across public and private sectors. A range of interconnected initiatives including national plans, standards and guidelines, performance indicators and outcomes measures and benchmarking and reporting processes are the key components of this nationally coordinated system.

\author{
Keywords \\ improvement, standards \\ Curr Opin Psychiatry 22:610-618 \\ C) 2009 Wolters Kluwer Health | Lippincott Williams \& Wilkins \\ 0951-7367
}

mental health services, outcomes measures, performance indicators, quality

\section{Introduction}

The Quality in Australian Healthcare Study, published in 1995 [1], highlighted the convincing need for greater attention to the safety and quality of healthcare in Australia. Mirroring similar developments internationally, Australia has seen unprecedented attention since that time to improve the quality and effectiveness of healthcare. This study sets out the significant advances that have been made in Australia in progressing quality and outcome measurement and improvement in mental health services, including their relationship to developments within the broader health system.

\section{Organization of health and mental health services in Australia}

Australia has a federated system of government, with responsibilities divided between the federal government and six state governments. In addition, Australia has several territories, two of which are represented in government at the national level. Responsibility for health and mental health services is shared between federal and state and territory governments, providing a universal healthcare system with publicly funded access to medical, nursing and allied healthcare, public hospitals and pharmaceuticals. In a complex division of responsibilities, the federal government funds Medicare, a national insurance system that provides rebates for the majority of healthcare delivered by primary care and specialist practitioners in the private sector, and the Pharmaceutical Benefits System that subsidizes the majority of pharmaceuticals prescribed in Australia. It also funds healthcare services for eligible veterans, community-controlled Aboriginal and Torres Strait Islander primary healthcare, residential aged care facilities, and provides a rebate on private health insurance premiums and a national vaccine (immunization) scheme. State and territory governments receive funding from the federal government to underwrite their health service systems, which focus on the provision of free public hospitals and ambulatory care, including mental healthcare, community care, drug and alcohol services, prison health services and public dental care. State and territory governments also have responsibility for environmental health services and the regulation of health services and professions. Both levels of government fund a range of nongovernment services that provide clinical and nonclinical healthcare support services. There is also a range of privately financed healthcare services available, with approximately $44 \%$ of Australians having private health insurance [2]. 


\section{Key safety and quality developments in the health sector in Australia}

There is a range of developments in the health sector in Australia that provides an important context for understanding the developments in mental health services.

\section{National Health Performance Framework}

A National Health Performance Framework (NHPF) was commissioned by Australian Health Ministers and published in 2001. It aims to capture the dimensions of performance at a system level and support performance measurement [3]. Utilizing this framework, performance of a health system can be measured by the monitoring of inputs, outputs or outcomes. The NHPF is set out in Table 1. The development of performance measures within each of the domains facilitates the reporting and comparison of performance at all levels of the health system. The NHPF sets out selection criteria for individual performance indicators and sets of indicators to be included in the Framework. In addition, all indicators are required to be defined in technical specifications, in line with established national health information development processes, so that they can be incorporated into the National Health Data Dictionary [4].

\section{National Healthcare Agreement}

A new National Healthcare Agreement (NHA) has been agreed between the Australian Government and individual states and territories in 2009 [5]. This agreement identifies seven overarching objectives for the health system: prevention, primary and community health, hospital and related care, aged care, patient experience, social inclusion and indigenous health and sustainability. Under each of these objectives, a range of outcomes, progress measures and outputs are specified. National Partnership Agreements have also been developed that target reforms in specified areas, some of which have an impact on mental health [6]. Performance data will be required to inform the administration of the NHA and the National Partnership Agreements.

\section{Australian Commission on Safety and Quality in Healthcare}

The Australian Commission on Safety and Quality in Healthcare (ACSQHC) was established in 2006 for a time-limited period to develop a national strategic framework to improve safety and quality across the healthcare system in Australia [7]. The Commission's role is to lead and coordinate improvements in safety and quality in healthcare in Australia, set standards, disseminate knowledge, report publicly and provide strategic advice to Health Ministers. It operates to influence the safety and quality of health services through national leadership and strategic coordination but is not directly involved in the governance of health service delivery at either the federal or state and territory level.

\section{Australian Council on Healthcare Standards}

The Australian Council on Healthcare Standards (ACHS) is an independent not-for-profit organization, dedicated to improve the quality of healthcare in Australia through continual review of performance, assessment and accreditation [8]. ACHS established clinical indicators for healthcare organizations in 1989 in association with Australian and New Zealand medical colleges, associations and societies. Within the mental health sector, ACHS has established an inpatient indicator set that collects data on diagnosis, discharge summaries, physical examinations, medication use, complications and incidents, and a community indicator set that focuses on frequency of community contact and admissions to hospital from community care. Participation in ACHS activity by healthcare organizations is voluntary.

\section{Weaving the threads of governance and reporting}

In line with their varied origins and reporting lines, there is, as yet, limited interplay between the data sets referred to above. Reflecting its primary purpose as a funding agreement that articulates the division of responsibilities between governments, the NHA does not currently reference the NHPF in its reporting framework, although it does mandate the collection of agreed minimum data sets used for constructing the NHPF. Rather, the NHA focuses on a limited number of population-based broad health indicators such as the treated prevalence rate of mental illness and the number of mental health services in the public and private sectors. The ACSQHC has commissioned work on a data set of safety and quality indicators for Australia as well as on the use of existing data sets to supplement safety and quality indicators. The extent to which this work will be informed by the NHPF and the ACHS indicators sets and the mandated reporting that will be required against this data set are uncertain as it has not yet been completed. All jurisdictional Health Ministers meet formally as the Australian Health Minister's Conference; this body is supported by the Australian Health Ministers' Advisory Council, which consists of the chief executives of all jurisdictional health departments. The ACSQHC reports to Australian Health Ministers, and provides strategic advice to them. This governance structure provides the thread that weaves together the rich tapestry of policy, planning, performance and accountability of healthcare services in Australia. In turn, Health Ministers of each jurisdiction report through their respective First Minister to the Council of Australian Governments (COAGs) that represents the vehicle of a federated governance structure, which drives integration between the initiatives within the health sector and other sectors that have an impact on the social determinants of health and mental healthcare. 


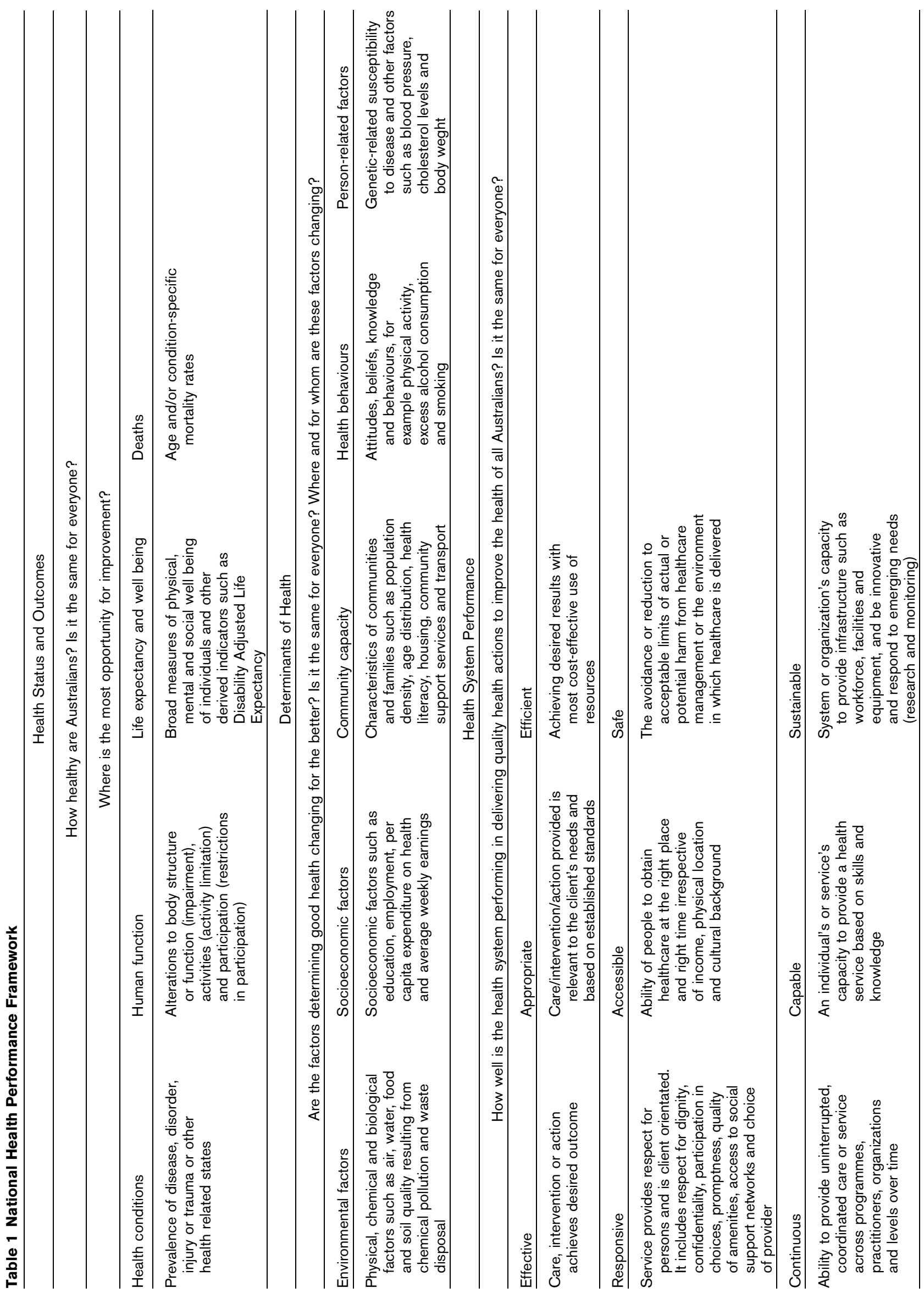




\section{Key safety and quality developments in the mental health sector in Australia}

Australia has adopted a strategic national approach to mental health reform, including the development of a mental health information strategy.

\section{National mental health strategy}

Australia has had a National Mental Health Strategy since 1992, which has provided a strong policy platform to guide mental health service reform. The National Mental Health Strategy is informed by a Statement of Mental Health Rights and Responsibilities [9] and the National Mental Health Policy [10], which was recently revised $\left[11^{\bullet}\right]$. Strategic priorities set out in the Policy have been operationalized via a series of 5-year National Mental Health Plans [12-14], each of which has been evaluated to inform the development of its successor $[15,16]$. The Fourth National Mental Health Plan is currently in development. The National Mental Health Strategy has also been supported by funding dedicated for mental health service reform, outlined in bilateral funding agreements between the Commonwealth and State/Territory governments [17]. The role of overseeing the implementation of the National Mental Health Strategy is allocated to the Mental Health Standing Committee (MHSC), a subcommittee of the Australian Health Ministers Advisory Council. In turn, MHSC has two key subcommittees, the Mental Health Information Strategy Subcommittee (MHISS) and the Safety and Quality Partnership Subcommittee (SQPS).

\section{Council of Australian Governments National Action Plan on Mental Health}

Despite the progress in service reform achieved throughout the life of the National Mental Health Strategy in Australia, concerns remain about the performance of mental health services [18,19]. In response to these concerns, the COAGs launched the National Action Plan on Mental Health 2006-2011 [20]. This plan presented a whole of government approach to mental health service delivery to complement the existing National Mental Health Plan 2003-2008, already being implemented under the auspices of Health Ministers. There are 12 progress measures included in the COAG National Action Plan.

\section{National mental health information priorities}

The document Mental Health Information Development: National Information Priorities and Strategies under the Second National Mental Health Plan [21] sets out a vision for an information infrastructure at the service delivery level. Funding was provided to support this information development in states and territories that agreed, in return, to collect information about the cost, quality and outcome of Australia's mental health services [22].

\section{National Mental Health Performance Framework}

Mirroring the structure and domains of the NHPF, the National Mental Health Performance Framework (NMHPF) [23] was established in 2005 to monitor the performance of public mental health services. Thirteen phase 1 indicators were developed that were able to be introduced immediately on the basis of the data already collected by states and territories. However, not all domains of the framework were able to be addressed within the phase 1 indicators due to limitations of the available data set. Phase 2 indicators that required further developmental work were identified; three of these have now been completed. The NMHPF with phase 1 and phase 2 indicators is set out in Table 2.

\section{National Mental Health Benchmarking Project}

To progress the implementation of the NMHPF indicators, selected mental health services across Australia were funded to participate in a National Mental Health Benchmarking Project [24]. Separate time-limited benchmarking forums were established for child and adolescent, adult, older persons and forensic mental health services. The project aimed to promote benchmarking by mental health organizations and to understand the issues that might have an impact on its use nationally as a quality improvement process. The project has now concluded, and an evaluation report is pending.

\section{Mental Health National Outcomes and Casemix Collection}

Australia has also taken a national approach to outcome measurement in public sector mental health services, and is considered a world leader in this regard [25]. Routine measurement of consumer outcomes is now in place in an estimated $85 \%$ of public mental health services. A range of instruments as outlined in Table $3\left(\left[26-36,37^{\bullet \bullet}\right]\right)$ are administered under the Mental Health National Outcomes and Casemix Collection (MH-NOCG) protocol [26]. The protocol utilizes both clinician-rated and consumer-rated measures and specifies the points at which measures must be collected. These include at admission (e.g. new referral and transfer from other setting), at review (usually 91 days) and at discharge (e.g. no further care, change of setting and death). The data are collated at a mental health service organization level, and then at a state or territory level, and are submitted to Australian Mental Health Outcomes and Casemix Network (AMHOCN) (see below), which analyses and reports on the data.

\section{Australian Mental Health Outcomes and Casemix Network}

The Australian Mental Health Outcomes and Casemix Network (AMHOCN) was established in 2003 to support the sustainable implementation of outcome measures 
Table 2 National Mental Health Performance Framework: mental health service organization performance indicators

\begin{tabular}{|c|c|c|}
\hline Domain & Subdomain & Indicator \\
\hline \multirow[t]{2}{*}{ Effective } & $\begin{array}{l}\text { Consumer outcomes } \\
\text { Carer outcomes }\end{array}$ & ${ }_{a}^{a}$ Changing consumers' clinical outcomes ${ }^{b}$ \\
\hline & Community tenure & 28-day readmission rate \\
\hline Appropriate & $\begin{array}{l}\text { Compliance with standards } \\
\text { Relevance to client needs }\end{array}$ & $\underset{\mathrm{a}}{\text { National Service Standards compliance }}$ \\
\hline \multirow[t]{2}{*}{ Efficient } & Inpatient care & $\begin{array}{l}\text { Cost per acute inpatient episode } \\
\text { Average length of acute inpatient stay }\end{array}$ \\
\hline & Community care & $\begin{array}{l}\text { Cost per 3-month community care period } \\
\text { Treatment days per 3-month community care period }\end{array}$ \\
\hline \multirow[t]{3}{*}{ Accessible } & Access for those in need & $\begin{array}{l}\text { Population receiving care } \\
\text { New client index }\end{array}$ \\
\hline & Local access & $\begin{array}{l}\text { Comparative area resources } \\
\text { Local access to inpatient care }\end{array}$ \\
\hline & Emergency response & a \\
\hline \multirow[t]{2}{*}{ Continuous } & Continuity between providers & a \\
\hline & $\begin{array}{l}\text { Cross-setting continuity } \\
\text { Continuity over time }\end{array}$ & $\begin{array}{l}\text { Preadmission community care } \\
\text { Postdischarge community care } \\
\text { a }\end{array}$ \\
\hline \multirow[t]{2}{*}{ Responsive } & Client perception of care & a \\
\hline & Consumer and carer participation & ${ }^{\mathrm{a} C}$ Consumer outcome participation \\
\hline \multirow[t]{2}{*}{ Capable } & Provider knowledge and skill & a \\
\hline & Outcomes orientation & Outcomes readiness \\
\hline Safe & & ${ }^{\mathrm{a}}$ Rate of seclusion \\
\hline \multirow[t]{3}{*}{ Sustainable } & Workforce planning & a \\
\hline & Training investment & a \\
\hline & Research investment & a \\
\hline
\end{tabular}

${ }^{\text {a }}$ Phase 2 indicators for development.

${ }^{b}$ This indicator has been agreed by the Mental Health Information Strategy Subcommittee but is awaiting final endorsement by the Mental Health Standing Committee (personal communication by Dr Aaron Groves, Chair, Mental Health Standing Committee).

as part of routine clinical practice $\left[37^{\bullet \bullet}\right]$. Broadly, the AMHOCN performs three roles: a data bureau responsible for receiving and processing data submitted by states and territories; analysis and reporting of mental health outcomes and casemix information at a national level and a training and service development resource centre. Over 12000 clinicians in Australia have received training in outcomes measurement.

Table 3 Administration of outcome measures according to the Mental Health National Outcomes and Casemix Collection protocol

\begin{tabular}{|c|c|c|c|c|c|c|c|c|c|}
\hline & \multicolumn{3}{|c|}{ Inpatient } & \multicolumn{3}{|c|}{ Community residential } & \multicolumn{3}{|c|}{ Ambulatory } \\
\hline \multicolumn{10}{|l|}{ Children and adolescents } \\
\hline CGAS & - & • & - & - & • & - & • & $\bullet$ & - \\
\hline FIHS & - & • & • & - & • & • & - & • & • \\
\hline Principal and additional diagnoses & - & • & • & - & • & • & - & • & • \\
\hline HoNOS & • & • & • & - & • & - & • & - & - \\
\hline LSP-16 & - & - & - & - & - & - & - & • & $\bullet$ \\
\hline Consumer self-report & - & - & - & $\bullet$ & $\bullet$ & $\bullet$ & $\bullet$ & $\bullet$ & $\bullet$ \\
\hline Principal and additional diagnoses & - & • & • & - & • & • & - & • & • \\
\hline Focus of care & - & - & - & - & - & - & - & • & • \\
\hline Mental health legal status & - & • & • & - & - & - & - & • & • \\
\hline \multicolumn{10}{|l|}{ Older persons } \\
\hline Focus of care & - & - & - & - & - & - & - & • & • \\
\hline Mental health legal status & - & • & • & - & • & • & - & • & • \\
\hline
\end{tabular}

BASIS-32, Behaviour and Symptom Identification Scale - Consumer-rated [30]; CGAS, Children's Global Assessment Scale - Clinician-rated [33]; HoNOS, Health of the Nation Outcome Scales - Clinician-rated [27]; HoNOS 65+, Health of the Nation Outcome Scales 65+ (Clinician-rated) [35]; HoNOSCA, Health of the Nation Outcome Scales for Children and Adolescents - Clinician-rated [32]; K-10+, Kessler 10 Plus - Consumer-rated [31]; LSP-16, Life Skills Profile 16 - Clinician-rated [28]; MHI, Mental Health Inventory - Consumer-rated [29]; RUG-ADL, Resource Utilization Groups - Activities of Daily Living (Clinician-rated) [36]; SDQ, Strengths and Difficulties Questionnaire [34]. Adapted from [26]. 


\section{Private Mental Health Alliance Centralized Data Management Service}

Since 2001, participating private psychiatric hospitals in Australia have also been implementing routine outcome measures [38], with an estimated $98 \%$ of private hospitals now included. Clinician-rated and consumer-rated measures (Health of the Nation Outcome Scales/Health of the Nation Outcome Scales 65+ and the MHQ-14) are taken at admission and discharge from hospital (including day programmes) and every 3 months for those with extended periods of care. The outcomes data are then submitted, in a de-identified format, to the Centralised Data Management Service, which prepares reports that are distributed to participating hospitals and private health insurers [39].

\section{National safety priorities in mental health: a national plan for reducing harm}

Through the SQPS, Australia has a mechanism for the implementation of nationally coordinated initiatives to achieve improvements in the safety and quality of mental health services. The document National Safety Priorities in Mental Health: a National Plan for Reducing Harm [40] has guided this work. Four priority areas are identified: reducing suicide and deliberate self-harm in mental health settings; reducing use of, and, where possible, eliminating, restraint and seclusion; reducing adverse drug events in mental health services and safe transport of people experiencing mental disorders. A national project $\left[41^{\bullet}\right]$ to reduce the use of seclusion and restraint has been implemented and has informed the development of the phase 2 performance indicator in the safety domain of the NMHPF. A representative of the ACSQHC sits on the SQPS, providing a strategic link to national safety and quality developments.

\section{National standards and guidelines}

National Standards for Mental Health Services [42] were endorsed in 1996 to guide service delivery and to assist in continuous improvement. Designed to complement the national service standards, National Practice Standards for the Mental Health Workforce [43] were endorsed in 2002. They address the shared knowledge and skills required by mental health professionals when working in a multidisciplinary mental health environment. Evidence-based practice guidelines have also been commissioned under the auspices of the National Mental Health Strategy [44-49].

\section{Monitoring and reporting on Australian mental health service performance}

Australia has in place extensive monitoring and reporting of mental health services. Four national minimum data sets are collected annually. These include: Admitted Patient Mental Healthcare, Residential Mental Health- care, Community Mental Healthcare and Mental Health Establishments. Three key national documents report on the performance of the mental health sector: the mental health services in Australia [50], National Mental Health Report [51] and Report on Government Services [52]. In addition to the above, states and territories also provide an annual report on their performance against the progress measures outlined in the COAG National Action Plan on Mental Health [53 ${ }^{\bullet}$.

\section{Mental Health National Outcomes and Casemix Collection}

AMHOCN reports on the MH-NOCG data utilizing both paper-based and electronic reports [54], including a flexible report portal that allows users to navigate directly to the specific table of interest. Significant effort has also gone into considering issues such as the meaning of 'clinically significant change' and how best to measure such change $\left[55,56^{\bullet \bullet}\right]$. Three Outcomes Expert Reference Groups have been established to inform the further development of outcome measures and casemix classification. Tools that can assist in the implementation of outcome measures at the service organization level have also been developed, including a web-based decision support tool that assists clinicians and service managers to compare their own clients against normative data, and a library of clinical prompts that can assist junior mental health clinicians in using outcome measures $\left[57^{\bullet}\right]$.

\section{Australian Council on Healthcare Standards cinical indicators}

The ACHS data set contains clinical indicators for both inpatient and community-based mental health services. The mental health inpatient data set contains 28 indicators across the domains of appropriateness, effectiveness, safety, continuity and accessibility, whereas the community data set has six indicators across the domains of accessibility and effectiveness [58]. The latest edition of the report Australasian Clinical Indicator Report: 2001 to $2007\left[^{\left[59^{\circ}\right]}\right.$ summarizes data provided for the years $2001-$ 2007.

\section{Discussion}

Despite the challenges of a federated health system, Australia has adopted a strategic national approach to the reform of mental health services, including a substantial investment in a range of interconnected initiatives to achieve quality improvement. This approach incorporates national plans, including an information development plan, practice and service standards, clinical guidelines, performance indicators and outcome measures, benchmarking and national reporting, and is consistent with developments across the broader health sector in Australia. 
Two approaches are utilized with respect to the use of data to improve service quality and performance: summative mechanisms, used primarily for the purpose of achieving external accountability, for example, to governments, and formative mechanisms that are essentially internally driven to achieve continuous quality improvement. The former uses data to establish comparative levels of performance, whereas the latter uses data and benchmarking processes as a starting point for identifying important issues and engaging stakeholders in dialogue to generate insights into practice [60].

Not unexpectedly for such an ambitious quality improvement programme across a complex health system, many challenges have been encountered. Successfully engaging stakeholders is a complex task that requires negotiation at many levels. This challenge underpins the limitations in data volume and quality that continue to be experienced, despite reports in which outcomes data have been used to affirm the value of the service system by clearly demonstrating that people in contact with public sector mental health services generally do get better [61]. Further work is required to ensure services and clinicians fully embrace these quality improvement initiatives as part of routine practice.

Added to this is the inherent limitation of any measurement collection. One such limitation of the work on outcomes measurement to date is that it has not been possible to guarantee like-with-like comparisons [62]. It is well recognized that outcome measures can be confounded by patient mix as well as by the quality of care. For example, if Service A achieves better outcomes than Service $\mathrm{B}$, it may be because it is providing more optimal care to a similar group of consumers or because it is providing the same quality care to a group of consumers with less complex needs. The reports produced to date on the MH-NOCC data do not answer the question of which factors are most influencing the outcomes of care. To address this vexed issue, work on developing 'case complexity adjustments' (also known as 'risk adjustment' or 'severity adjustment') [63"] will continue over coming years, building on the findings of the Mental Health Classification and Service Cost project conducted in Australia in the late 1990s [64].

Another concern is that the approach used to report outcomes separates a consumer's care into segments (hospital vs. community) rather than tracking the person's overall outcome across treatment settings. A further criticism is that the outcome measures do not reflect the aspects of care considered most beneficial for recovery by consumers $\left[65^{\circ}\right]$. The recovery paradigm has risen to prominence in Australia over the past 5 years [66 $6^{\circ}$, yet few performance indicators of recovery are in routine use. Work is progressing on alternate ways to measure consumer and carer experience of mental healthcare $[67,68]$. Performance measures also need to be culturally responsive to indigenous and other ethnic groups [69], and this may require modification of core performance measures. For example, Santhanam et al. [70] adapted the NMHPF by adding measures for two additional service dimensions relating to community engagement and therapeutic care, noting that a service must be locally responsive, contextually sensitive and culturally sensitive.

\section{Conclusion}

Despite the challenges of a federated system of healthcare and the division of healthcare across public and private sectors, Australia has implemented a strategic national approach to mental health service improvement that weaves together national plans, standards and guidelines, performance indicators and outcomes measures and benchmarking and reporting processes that can be applied across public and private sectors. However, many challenges remain for the future, particularly the need for strong clinical leadership and continued government collaboration [71] to maximize the return on the investment to date.

\section{Acknowledgement}

The authors would like to thank Dr Aaron Groves for offering advice on this paper.

\section{References and recommended reading}

Papers of particular interest, published within the annual period of review, have been highlighted as:

- of special interest

- of outstanding interest

Additional references related to this topic can also be found in the Current World Literature section in this issue (p. 657).

1 Wilson R, Runciman W, Gibberd R, et al. The Quality in Australian Healthcare Study. Med J Aust 1995; 163:458-467.

2 Australian Institute of Health and Welfare. Australia's health 2008. Cat. No. AUS 99 Canberra: AlHW; 2008.

3 National Health Performance Committee. National Health Performance Framework Report. Brisbane: Queensland Health; 2001.

4 Australian Institute of Health and Welfare. National health data dictionary. Canberra: AlHW; 2000.

5 Council of Australian Governments. National healthcare agreement; 2009. http://www.coag.gov.au/intergov agreements/federal financial relations/ docs/IGA_FFR_ScheduleF_National_Healthcare_Agreement.rtf. [Accessed April 2009].

6 Australian Government. Budget 2009-10; 2009. http://www.budget.gov.au/ 2009-10/content/bp3/html/bp3_payments.htm. [Accessed May 2009].

7 Australian Commission on Safety and Quality in Healthcare; 2009. http:// www.safetyandquality.gov.au/. [Accessed April 2009].

8 Australian Council on Healthcare Standards; 2009. http://www.achs.org.au/ aboutus/. [Accessed May 2009].

9 Australian Health Ministers. Mental Health Statement of Rights and Responsibilities. Canberra: Australian Government Publishing Service; 1991.

10 Australian Health Ministers. National Mental Health Policy. Canberra: Australian Government Publishing Service; 1992.

11 Australian Health Ministers. National Mental Health Policy 2008. Canberra: - Australian Government; 2009.

A contemporary statement of key priorities for mental health service delivery in Australia.

12 Australian Health Ministers. National Mental Health Plan. Canberra: Commonwealth Department of Health and Family Services; 1993. 
13 Australian Health Ministers. Second National Mental Health Plan. Canberra: Commonwealth Department of Health and Family Services; 1998.

14 Australian Health Ministers. National Mental Health Plan 2003-2008. Canberra: Commonwealth Government; 2003.

15 National Mental Health Strategy Evaluation Steering Committee. Evaluation of the National Mental Health Strategy: final report. Canberra: Commonwealth Department of Health and Family Services; 1997.

16 Steering Committee for the National Mental Health Plan. Evaluation of the Second National Mental Health Plan. Canberra: Commonwealth Department of Health and Ageing; 2003.

17 Department of Health and Ageing. Australian healthcare agreements; 2003. http://www.health.gov.au/internet/main/publishing.nsf/Content/health-ahcaagreement.htm. [Accessed April 2009].

18 Mental Health Council of Australia. Not for service: experiences of injustice and despair in the mental healthcare in Australia. Canberra: Mental Health Council of Australia; 2005.

19 Senate Select Committee on Mental Health. A national approach to mental health-from crisis to community. Canberra: Parliament of Australia; 2006.

20 Council of Australian Governments. National Action Plan on Mental Health 2006-2011; 2006. http://www.coag.gov.au/coag_meeting_outcomes/ 2006-07-14/docs/nap_mental_health.pdf. [Accessed April 2009].

21 Department of Health and Aged Care. Mental Health Information Development: National Information Priorities and Strategies under the Second National Mental Health Plan 1998-2003. Canberra: Commonwealth of Australia; 1999.

22 Eagar K, Burgess P, Buckingham, B. Towards National Benchmarks for Australian Mental Health Services. ISC Discussion paper no. 4. Canberra: Commonwealth Department of Health and Ageing; 2003.

23 NMHWG Information Strategy Committee Performance Indicator Drafting Group. Key Performance Indicators for Australian Public Mental Health Services. ISC Discussion paper no. 5. Canberra: Australian Government Department of Health and Ageing; 2005.

24 AMHOCN. National Mental Health Benchmarking Project; 2006. http:// www.mhnocc.org/Benchmarking/BenchmarkingProject/. [Accessed April 2009].

25 Slade M. Routine outcome assessment in mental health services. Psychol Med 2002; 32:1339-1343.

26 Department of Health and Ageing. Mental Health National Outcomes and Casemix Collection: Technical Specification of State and Territory Reporting Requirements for the Outcomes and Casemix components of 'Agreed Data' (Version 1.50). Canberra: Department of Health and Ageing; 2003.

27 Wing J, Beevor A, Curtis R, et al. Health of the Nation Outcome Scales (HoNOS): research and development. Br J Psychiatry 1998; 172:11-18.

28 Parker G, Rosen A, Emdur N, Hadzi-Pavlovic D. The life skills profile: psychometric properties of a measure assessing function and disability in schizophrenia. Acta Psychiatr Scand 1991; 83:145-152.

29 Veit C, Ware J. The structure of psychological distress and well being in general populations. J Consult Clin Psychol 1983; 51:730-742.

30 Eisen S, Dill D, Grob M. A self-report symptom and problem rating scale to increase inpatients' involvement in treatment. Psych Serv 2000; 51:349353.

31 Kessler R, Andrews G, Colpe L, et al. Short screening scales to monitor population prevalences and trends in nonspecific psychological distress. Psychol Med 2002; 32:959-976.

32 Gowers S, Harrington R, Whitton A, et al. Brief scale for measuring the outcomes of emotional and behavioural disorders in children. Health of the Nation Outcome Scales for children and Adolescents (HoNOSCA). Br J Psychiatry 1999; 174:413-416.

33 Schaffer D, Gould M, Brasic J, et al. A children's global assessment scale (CGAS). Arch Gen Psychiatry 1983; 40:1228-1231.

34 Goodman R. The Strengths and Difficulties Questionnaire: A research note. J Child Psychol Psychiatry 1997; 38:581-586.

35 Burns A, Beevor A, Lelliott $P$, et al. Health of the Nation Outcome Scales for elderly people (HoNOS 65+). Glossary for HoNOS $65+$ score sheet. Br J Psychiatry 1999; 174:435-438.

36 Fries B, Schneider D, Foley W, et al. Refining a case-mix measure for nursing homes: resource utilization groups (RUG-III). Med Care 1994; 32:668-685.

37 Australian Mental Health Outcomes and Classification Network; 2009. http:// - www.mhnocc.org/amhocn/. [Accessed May 2009].

A comprehensive resource supporting the implementation of routine outcome measures in public mental health services in Australia.
38 Morris-Yates A. The Strategic Planning Group for Private Psychiatric Services Data Collection and Analysis Working Group. A National Model for the Collection and Analysis of a Minimum Data Set with Outcome Measures for Private, Hospital-based, Psychiatric Services. Canberra: Strategic Planning Group for Private Psychiatric Services; 2000.

39 Private Mental Health Alliance. Centralised data management services; 2001. http://www.pmha.com.au/cdms/home. [Accessed April 2009].

40 National Mental Health Working Group. National safety priorities in mental health: a national plan for reducing harm. Canberra: Department of Health and Ageing; 2005.

41 National Seclusion and Restraint Project; 2009. http://www.nmhsrp.gov.au/ - $\quad \mathrm{c} / \mathrm{mh}$. [Accessed May 2009].

A nationally coordinated initiative to support a change in knowledge, skills, attitude and practice in relation to the use of seclusion and restraint in mental health services in Australia.

42 Australian Health Ministers Advisory Council National Mental Heath Working Group. National Standards for Mental Health Services. Canberra: Commonwealth of Australia; 1996.

43 National Mental Health Education and Training Advisory Group. National Practice Standards for the Mental Health Workforce. Canberra: Department of Health and Ageing; 2002.

44 Royal Australian and New Zealand College of Psychiatrists Clinical Practice Guidelines Team for the Treatment of Schizophrenia and Related Disorders. Royal Australian and New Zealand College of Psychiatrists clinical practice guidelines for the treatment of schizophrenia and related disorders. Aust N Z J Psychiatry 2005; 39:1-30.

45 Royal Australian and New Zealand College of Psychiatrists Clinical Practice Guidelines Team for Deliberate Self-harm. Royal Australian and New Zealand clinical practice guidelines for the management of adult deliberate self-harm. Aust N Z J Psychiatry 2004; 38:868-884.

46 Beumont $\mathrm{P}$, Hay $\mathrm{P}$, Beumont $\mathrm{D}$, et al. Royal Australian and New Zealand College of Psychiatry Clinical Practice Guidelines Team for Anorexia Nervosa. Australian and New Zealand clinical practice guidelines for the treatment of anorexia nervosa. Aust N Z J Psychiatry 2004; 38:659-670.

47 Ellis P. Royal Australian and New Zealand College of Psychiatry Clinical Practice Guidelines Team for Depression. Australian and New Zealand clinical practice guidelines for the treatment of depression. Aust $\mathrm{N} \mathrm{Z} \mathrm{J}$ Psychiatry 2004; 38:389-407.

48 Royal Australian and New Zealand College of Psychiatry Clinical Practice Guidelines Team for Bipolar Disorder. Australian and New Zealand clinical practice guidelines for the treatment of bipolar disorder. Aust N Z J Psychiatry 2004; 38:280-305.

49 Royal Australian and New Zealand College of Psychiatry Clinical Practice Guidelines Team for Panic Disorder and Agoraphobia. Australian and New Zealand clinical practice guidelines for the treatment of panic disorder and agoraphobia. Aust N Z J Psychiatry 2003; 37:641-656.

50 Australian Institute of Health and Welfare. Mental health services in Australia 2005-06. Mental health series no. 10. Cat. No. HSE 56. Canberra: AIHW; 2008.

51 Department of Health and Ageing. National Mental Health Report 2007: Summary of Twelve Years of Reform in Australia's Mental Health Services under the National Mental Health Strategy 1993-2005. Canberra: Commonwealth of Australia; 2007.

52 Steering Committee for the Review of Government Service Provision.

- Report on Government Services 2009. Melbourne: Productivity Commission; 2009.

A national report providing national and jurisdictional comparisons on a range of mental health service performance measures.

53 Council of Australian Governments. National Action Plan for Mental

- Health 2006-2011 Progress Report 2006-07; 2008. http://www.coag. gov.au/reports/docs/AHMC_COAG_mental_health.doc. [Accessed April 2009].

The first national report on performance by jurisdictions following the implementation of the COAG National Action Plan on Mental Health.

54 AMHOCN First Edition Reports; 2005. http://www.mhnocc.org/amhocn/ Reports/. [Accessed May 2009].

55 Burgess P, Pirkis J, Coombs T. Modelling candidate effectiveness indicators for mental health services. Aust N Z J Psychiatry 2009; 43:531538.

56 Burgess $\mathrm{P}$, Trauer T, Coombs $\mathrm{T}$, et al. What does 'clinical significance' mean - 1 in the context of the Health of the Nation Outcome Scales? Australas Psychiatry 2009; 17:141-148.

An excellent insight into the challenges of clinical interpretation of mental health outcome measures informed by the results of the routine implementation of the HONOS in Australia. 
57 McKay $\mathrm{R}$, Coombs $\mathrm{T}$, Burgess $\mathrm{P}$, et al. Development of clinical prompts to

- enhance decision support tools related to the National Outcomes and Casemix Classification. Version 1.0, Sydney; 2008. Australian Mental Health Outcomes and Classifications Network. http://www.mhnocc.org/amhocn/ Clinical\%20Prompts_Final\%20Report_20080530_Final.pdf. [Accessed April 2009].

Providing practical support for clinicians will enhance the routine use of outcome measures.

58 Australian Council on Healthcare Standards. Clinical Indicator Summary Guide 2009, Ultimo: ACHS; 2009.

59 Australian Council on Healthcare Standards. Australasian Clinical Indicator

- Report: 2001 to 2007, determining the potential to improve. 9th ed. Ultimo: ACHS; 2008.

Service benchmarking against defined clinical indicators promotes continuous quality improvements processes within mental health services.

60 Gardner K, Sibthorpe B, Longstaff D. National quality and performance system for Divisions of General Practice: early reflections on a system under development. Australia and New Zealand Health Policy 2008; 5:8.

61 Burgess P, Pirkis J, Coombs T. Do adults in contact with Australia's public sector mental health services get better? Aust New Zealand Health Policy 2006; 3:9.

62 Pirkis J, Burgess $\mathrm{P}$, Coombs T, et al. Routine measurement of outcomes in Australian public sector mental health services. Aust New Zealand Health Policy 2005; 2:8.

63 Burgess P, Pirkis J. Case complexity adjustment and mental health outcomes:

- conceptual issues (Version 1.0). Brisbane; Australian Mental Health Outcomes and Classification Network; 2009.

An important study that articulates significant issues in relation to the impact of case complexity in interpreting outcomes in mental health services.
64 Buckingham B, Burgess $\mathrm{P}$, Soloman S, et al. Developing a casemix classification for mental health services. Canberra: Commonwealth Department of Health and Family Services; 1998.

65 Happell B. Determining the effectiveness of mental health services from a - consumer perspective: part 1 - enhancing recovery. Int J Ment Health Nurs $2008 ; 27: 116-122$.

A timely reminder that the effectiveness of mental health services can be assessed from different perspectives.

66 Senate Standing Committee on Community Affairs. Towards recovery: mental - $\quad$ health services in Australia. Canberra: Parliament House; 2008.

Report from the Australian Senate Standing Committee on progress in mental health service reform in Australia.

67 NSW Consumer Advisory Group. A statewide approach to measuring and responding to consumer perceptions and experiences of adult mental health services. Sydney: NSW Department of Health; 2006.

68 Department of Human Services. Consumer and carer experience of care and support:a mental health quality improvement initiative; 2009. http://www.health. vic.gov.au/mentalhealth/quality/consumer.htm\#key. [Accessed May 2009].

69 O'Brien A, Boddy J, Hardy D. Culturally specific process measures to improve mental health clinical practice: indigenous focus. Aust N Z J Psychiatry 2007; 41:667-674

70 Santhanam R, McEwan A, Bainbridge R, et al. Adapting the Australian Mental Health Performance Indicators to the contextual needs of a Remote Area Child and Youth Mental Health Services; 2007. http://healthbulletin.org.au/ wp-content/uploads/2009/01/bulletin_original_articles_santhanam.pdf. [Accessed April 2009].

71 Pirkis J, Callaly T. Mental health outcome measurement in Australia. In: T. Trauer, editor. Outcome measurement in mental health. Cambridge: Cambridge University Press (in press). 